\title{
A INFLUÊNCIA DA REPRODUÇÃO CULTURAL SOBRE O HÁBITO DE SUCÇÃO DE CHUPETA
}

\section{THE INFLUENCE OF CULTURAL REPRODUCTION ON THE PACIFIER SUCKING HABIT}

\author{
Maria Luiza M. Mendes ${ }^{1}$ \\ Ana Carolina Gluszevicz ${ }^{2}$ \\ Mariana Domingos Saldanha ${ }^{3}$ \\ Vanessa Polina Pereira Costa ${ }^{4}$ \\ Ruth Irmgard Bärtschi Gabatz ${ }^{5}$ \\ Douver Michelon ${ }^{6}$
}

\begin{abstract}
Resumo: O objetivo deste estudo foi conhecer a percepção dos pais sobre o hábito da sucção de chupeta de seus filhos, além de descrever as experiências relacionadas à utilização desse objeto. Trata-se de uma pesquisa qualitativa, realizada com 10 pais de pré-escolares que participaram da estratégia motivacional para remoção de chupeta, realizada através de atividade lúdica nas escolas. As entrevistas foram gravadas e transcritas, logo após foram ponderadas por meio da análise de conteúdo temática. A partir das entrevistas ficou evidente que a prática da utilização da chupeta está fortemente relacionada à cultura, e que os pais percebem este como um hábito comum e presente na criação de seus filhos. Apesar de entenderem que o hábito prolongado pode ser prejudicial, enfrentam dificuldades para a remoção do mesmo. Enfatiza-se que a cultura é transformável, sendo necessária uma abordagem participativa construída a partir de novas técnicas de educação em saúde.
\end{abstract}

Palavras-chave: Chupeta; Motivação; Pesquisa qualitativa; Cultura; Pré-escolar.

Abstract: The aim of this study was know the parents' perception about the pacifier sucking habits of their children, as well as to describe the experiences related to the use of this object. This is a qualitative research carried out with 10 preschool parents who participated in the motivational strategy for pacifier removal, performed through playful activity in schools. The interviews were recorded and transcribed, soon after they were weighted through the thematic content analysis. From the interviews, it was evident that the practice of using the pacifier is strongly related to culture, and that parents perceive this as a common habit and present in the creation of their children. Although they understand that the prolonged habit can be harmful, they face difficulties for the removal of the same. It is emphasized that the culture is transformable, being necessary a participative approach constructed from new techniques of education in health.

\footnotetext{
${ }^{1}$ Cirurgiã-dentista. Residente em Saúde da Criança da Universidade Federal de Pelotas (UFPEL), Pelotas, RS, Brasil.E-mail: maria.mmendes@ hotmail.com

${ }^{2}$ Cirurgiã-dentista. Pós-Graduanda em Ortodontia da Faculdade Avantis (IGPGO), Caxias do Sul, RS, Brasil. E-mail: ana.carolina.g@ hotmail.com

${ }^{3}$ Enfermeira pela Universidade Federal de Pelotas (UFPEL), Pelotas, RS, Brasil. E-mail: marianadsaldanha@hotmail.com

${ }^{4}$ Doutora em Odontopediatria. Professora Adjunta em Odontopediatria da Universidade Federal de Pelotas (UFPEL), Pelotas, RS, Brasil. E-mail: polinatur@yahoo.com.br

${ }^{5}$ Doutora em Ciências da Saúde. Professora Adjunta da Faculdade de Enfermagem da Universidade Federal de Pelotas (UFPel), Pelotas, RS, Brasil. E-mail: r.gabatz@yahoo.com.br

${ }^{6}$ Doutor em Ortodontia. Professor Adjunto do Departamento de Odontologia Social e Preventiva da Faculdade de Odontologia, Universidade Federal de Pelotas (UFPel), Pelotas, RS, Brasil. E-mail: douvermichelon@gmail.com
} 
Keywords: Pacifier; Motivation; Qualitative research; Culture; Preschool child.

\section{Introdução}

A sucção inicia na vida intrauterina e se intensifica nos primeiros meses de vida da criança sendo um meio de contato entre ela e o mundo externo, além de suprir suas necessidades nutricionais e afetivas (BEE, 1997). Inicialmente o hábito é consciente, porém, logo que aumenta a frequência do mesmo este passa a ser inconsciente. A partir do momento em que estes hábitos causam alterações oclusais e comprometem o equilíbrio da neuromusculatura orofacial, são conhecidos como hábitos bucais deletérios (DE MATOS et al., 2017). O hábito de sucção não nutritiva como o uso da chupeta é uma prática amplamente difundida, tendo importante associação com distúrbios oclusais (TOMITA; BIJELLA; FRANCO, 2000).

A experiência adquirida pelas gerações se acumula em fenômenos ou objetos culturais, os quais passam por aperfeiçoamentos e modificações a partir da atividade social. Desse modo, o fenômeno cultural do oferecimento da chupeta às crianças por seus pais, assim como esse objeto cultural, transformou-se ao longo do tempo (DUARTE, 2004). Associado a representações sociais, a chupeta simboliza as crianças e é passada pelas gerações, sendo considerado um costume infantil (SERTÓRIO; SILVA 2005; FÓFANO et al., 2009). Além disso, o fator cultural da chupeta e o uso de hábitos orais deletérios pela família contribuem para a implantação e manutenção deste hábito entre as crianças (SERRA-NEGRA et al., 2006).

Hábitos bucais parafuncionais, como a interposição de objetos para a sucção tais como a chupeta, causam mudança de pressão e desequilíbrio entre as forças internas e externas na cavidade oral, alterando o desenvolvimento do sistema estomatognático e produzindo uma deformação nas estruturas bucais, o que acarreta em má oclusão, além de poder causar problemas psicológicos e em outros sistemas do organismo (AGURTO et al., 1999; DUQUE; ZUANON, 2006; EMMERICH et al., 2004; SERRA-NEGRA PORDEUS; ROCHA JUNIOR, 1997). Esse é mais prejudicial quando estabelecido precocemente e mantido em continuidade durante o crescimento e desenvolvimento da criança (PEREIRA; SCHARDOSIM; COSTA, 2009). Desse modo, investir na prevenção de más oclusões e em técnicas que auxiliem a descontinuação dos hábitos de sucção não nutritiva é de extrema importância. 
A intervenção precoce através da educação em saúde e eliminação dos fatores etiológicos das más oclusões pode prevenir desarmonias esqueléticas, dentárias e funcionais, o que caracteriza a ortodontia preventiva (SILVA; AMMON; SILVA, 1985). Pereira, Schardosim e Costa (2009) avaliaram uma estratégia motivacional para a remoção do hábito de sucção da chupeta em pré-escolares, realizada com 150 crianças na faixa etária de 4 a 6 anos de idade matriculadas em escolas de educação infantil públicas e privadas do município de Pelotas, Rio Grande do Sul (RS), Brasil.

No estudo foi observado que $24 \%$ dos pré-escolares faziam uso da chupeta, destes a maioria residiam com os pais e passavam a maior parte do tempo com eles quando não estavam na escola, tinham irmãos e ainda $63,6 \%$ das famílias relataram ter tentado a remoção do hábito deletério. O sucesso na remoção da chupeta foi observado em $66,7 \%$ das crianças que a utilizavam.

Sabe-se que a existência destes hábitos é comum em pré-escolares e que estes podem se manter persistentes, além da fase inicial da vida, de acordo com algumas características culturais, de costume, condição socioeconômica da família, escolaridade dos pais, entre outros (DE MATOS et al., 2017).

Tendo em vista êxito da estratégia motivacional apresentada e seus resultados que demonstram a participação familiar na utilização e remoção do hábito da sucção de chupeta das crianças, o objetivo deste estudo foi conhecer a percepção dos pais sobre o hábito da sucção de chupeta de seus filhos, além de descrever as experiências relacionadas à utilização desse objeto depois da aplicação do método de Pereira, Schardosim e Costa (2009) que estimulou a descontinuação do uso da chupeta em pré-escolares matriculados em escolas de educação infantil da cidade de Pelotas (RS).

\section{Caminho Metodológico}

Trata-se de uma pesquisa descritiva com abordagem qualitativa, realizada com 10 pais ou responsáveis legais de pré-escolares que participaram da estratégia motivacional para a remoção do hábito da sucção de chupeta, segundo Pereira, Schardosim e Costa (2009). Todas as crianças que participaram do estudo prévio, onde foi realizada a aplicação da estratégia motivacional, eram matriculadas em escolas de educação infantil da cidade de Pelotas-RS, com idades entre 3 e 6 anos.

A estratégia motivacional foi realizada em quatro fases: esclarecimento dos responsáveis sobre o estudo, apresentação e explicação do problema para a criança, 
realização de atividades lúdicas por meio de fantoches, slides e recurso motivacional (árvore de chupetas), em que as crianças eram estimuladas a colocar sua chupeta na árvore, a qual é decorada com purpurina (glitter) para que imaginem sua transformação em estrela, e avaliação feita através da contagem das chupetas na árvore, além da confirmação pelos pais do abandono do hábito.

A estratégia foi aplicada nas escolas em 4 encontros semanais com reforço de um encontro após o período de 1 mês. A avaliação da sua efetividade foi obtida a partir da contagem dos bicos na árvore de bicos e pela confirmação dos pais quanto à efetiva remoção do hábito. Após o período de dois meses da realização da intervenção com as crianças, os pais foram contatados através de ligação telefônica para realização da entrevista sobre a percepção da estratégia.

Os participantes da pesquisa foram definidos a partir do método de sorteio que foi realizado em duas etapas, um sorteio realizado apenas com os responsáveis das crianças que removeram o hábito deletério selecionando cinco responsáveis deste grupo, e o outro com os que não removeram o hábito, selecionando mais cinco responsáveis, totalizando 10 responsáveis para as entrevistas. A renda familiar foi coletada em salários mínimos, em que um salário mínimo correspondia ao valor de $\mathrm{R} \$ 880,00$ e a escolaridade dos pais foi categorizada em ensino fundamental, médio e superior.

A coleta de dados foi realizada por meio de entrevistas individuais semiestruturadas que foram gravadas e transcritas, realizadas no período de abril e maio de 2016. A análise dos dados ocorreu por meio da análise temática de conteúdo segundo Minayo (2013), este tipo de análise visa conhecer os núcleos de sentido das informações coletadas. Para tanto, realiza-se uma leitura exaustiva das informações em que os códigos iniciais (palavras, frases ou temas) são selecionados com base na frequência em que aparecem, separando-se os que mais aparecem. Após, classifica-se e agupa-se os dados em categorias temáticas, destacando as informações obtidas de acordo com os temas selecionados. Por fim, após o tratamento e interpretação dos resultados obtidos esses são discutidos comparando-os com a produção científica existente acerca dos temas selecionados.

A entrevista foi realizada na Faculdade de Odontologia em uma sala reservada, somente com a presença da mãe, enquanto a criança ficava em uma sala com brinquedos para que pudesse se distrair. As entrevistadoras foram duas alunas de graduação em Odontologia previamente treinadas para a aplicação da entrevista. 
O projeto foi avaliado e aprovado pelo Comitê de Ética em Pesquisa da Faculdade de Odontologia da Universidade Federal de Pelotas, através do parecer $n^{\circ}$ 1.468.593, segundo os termos da Resolução no 466/12 do Conselho Nacional de Saúde.

O Termo de Consentimento Livre e Esclarecido (TCLE) foi assinado pelos pais após terem sido fornecidas orientações aos responsáveis legais quanto ao objetivo da pesquisa, além da garantia a recusa da participação ou retirada do consentimento em qualquer momento e a privacidade dos indivíduos. Esta foi preservada por meio da identificação das entrevistas pela letra $\mathrm{P}(\mathrm{P} 1, \mathrm{P} 2 \ldots)$, correspondendo à inicial da palavra participante.

\section{Resultados e discussão}

Os responsáveis tinham escolaridade variante, de ensino fundamental a superior completo e renda familiar média que variou de um a cinco salários mínimos, sendo considerado o salário mínimo no valor de $\mathrm{R} \$ 880,00$. Para garantir e preservar a identidade dos responsáveis, as entrevistas foram identificadas pela letra $\mathrm{P}(\mathrm{P} 1, \mathrm{P} 2 \ldots)$, por ser a inicial da palavra participante.

A estratégia motivacional para a remoção do hábito de sucção de chupeta foi realizada nesse estudo com 77 crianças de ambos os sexos, de 3 a 6 anos de idade, as quais frequentavam duas escolas de educação infantil privadas de um município do sul do Brasil. O sucesso das ações foi observado em $68 \%$ das crianças.

A partir da análise das entrevistas, identificaram-se dois temas principais: utilização da chupeta e reprodução cultural do uso da chupeta.

\subsection{Utilização da chupeta}

A utilização da chupeta é um hábito frequente, sendo que o seu início ocorre, na maioria das vezes, já nos primeiros dias de vida da criança. Isso pode ser constatado nas falas de P3 e P4:

Saiu do hospital com o bico na boca já. Ele usa desde pequenininho [...] já saiu do hospital com o biquinho na boca, isso é culpa da mamãe né... (P3).

No primeiro dia que ele nasceu (P4).

Percebe-se por meio desses relatos que a chupeta é inserida precocemente na vida da criança pelos familiares, sendo apresentada desde seu nascimento e oferecida até mesmo no hospital. A chupeta faz parte dos enxovais das gestantes e já é vista como algo 
cultural, muitos familiares insistem em ofertá-la ao bebê logo nos primeiros dias de vida (FERNANDES; LIMA, 2019).

Desde bebê, no terceiro ou quarto dia eu já botei o bico na boca dele (P6).

$$
\text { [...] enfiaram o bico [...] ela já saiu chupando (P9). }
$$

Observa-se que nas fases iniciais da vida da criança é bastante comum a instalação do hábito de sucção da chupeta. Isso vem ao encontro de um estudo no qual foi identificado que ainda no hospital $80 \%$ das mães ofereceram a chupeta para seus filhos, na ocasião, mais da metade deles já iniciaram o hábito e aos quinze dias, $80 \%$ das crianças o adotaram (TOMASI; VICTORA; OLINTO 1994). Outra pesquisa revelou que durante a primeira semana de nascimento, sete em cada dez bebês já faziam o uso da chupeta (VICTORA et al., 1997). Ainda, no primeiro mês de vida sua utilização estimulada pelas famílias em 87,8\% dos bebês (SOARES et al., 2003). Nota-se assim a quantidade expressiva de crianças que fazem a utilização do objeto e a normalidade com que ele é tratado pelas famílias.

O uso da chupeta entre as mães brasileiras é muito difundido, apesar de poder gerar efeitos deletérios sobre a dentição e a amamentação, como confirma a Academia Americana de Pediatria e a Organização Mundial da Saúde (BRASIL, 2001; WORLD HEALTH ORGANIZATION; UNICEF 1989; AMERICAN ACADEMY OF PEDIATRICS, 2012). Dessa forma a prevalência de crianças que a utilizam é alta, variando de 53 à 85\% (BRASIL, 2001; VICTORA et al., 1997; SOARES et al., 2003; MARTINS et al., 2010; PRAETZEL et al., 2002). Observou-se em um estudo realizado com mães de crianças até quatro anos de idade, que mesmo elas tendo conhecimento dos danos causados pelo hábito de sucção de chupeta, mais da metade das mães a ofereceram aos seus filhos com objetivo de cessar o choro ou por costume (FÓFANO et al., 2009). Do mesmo modo, identificou-se que $42 \%$ das mães de crianças até quatro anos referiram que a chupeta prejudica os dentes, no entanto $82 \%$ delas permitiam que as crianças a utilizassem (PINTO et al., 2003).

Neste estudo também se evidenciou o uso da chupeta para acalmar as crianças:

[...] o bico ajuda a criança a ficar calma e tu acaba tentando sanar uma coisa e botando outro problema... (P4).

Emerge nesse depoimento que o participante tem consciência das consequências negativas do hábito de sucção da chupeta para a criança, sendo o mesmo considerado um problema, contudo o estimula, prevalecendo sua formação cultural de que o objeto tranquiliza seu filho não havendo outros recursos para esse fim. Ademais, pode ser notado 
na fala de P5, que apesar dos pais possuírem uma percepção negativa de crianças com o hábito deletério, consentem a utilização da chupeta devido ao apego do filho ao artefato, isso pode ocorrer pelo fato dos pais desejarem evitar situações que gerem estresse para seus filhos ou pela consciência da inabilidade para a sua retirada:

\section{Eu pensava: Ah vou tirar o bico dela que eu acho feio criança grande chupando bico. Acho coisa mais horrível. [...] fui deixando ela usar, foi indo, foi indo, ela era muito mais dependente também do bico né, aí foi muito mais difícil tirar... (P5).}

A fase oral, do nascimento até os dois anos de idade, é o primeiro estágio do desenvolvimento psicológico do ser humano. É através da cavidade oral que as crianças exercem as funções de reconhecimento do ambiente e de nutrição, sendo essenciais as estruturas orais e a sucção para o relacionamento do bebê com o mundo exterior (WALTER; FERELLE; ISSAO, 1996). Assim, associando a importância que a sucção tem para a criança, como incentivo do uso da chupeta pelos pais, as crianças acabam se tornando dependentes do objeto.

A necessidade de sucção está relacionada a fatores, tais como a fisiologia da criança, a maneira como a mãe a amamenta e o fator emocional (MASCARENHAS, 1999). De acordo com Hanson e Barret (1995) a origem dos hábitos de sucção não nutritiva deve ser pesquisada na primeira infância, podendo ser de ordem fisiológica, aprendizado condicionado e emocional. Assim, levando em consideração o fator emocional, quando o hábito perdura, além da necessidade fisiológica de sucção, pode estar ligado a tensões geradas através de estímulos que ameaçam a segurança da criança ou sua estima, como cobrança exagerada dos pais, divórcio, a chegada de um novo membro na família, críticas ou abusos dos irmãos, rejeição, concorrência com os colegas e discriminação, agressões ou carência (JORGE et al., 2000).

\section{[...]ele é muito sozinho ele não larga o bico, vamos dizer assim (P4).}

$\mathrm{Na}$ fala de $\mathrm{P} 4$, verifica-se que o bico tornou-se uma companhia para a criança, usando-o como uma forma de apoio emocional para o enfrentamento do sentimento de solidão, podendo dessa forma ser identificada a causa emocional do hábito de sucção não nutritiva. Destaca-se a importância, nesses casos, do envolvimento familiar para a remoção do hábito de sucção da chupeta de forma a atuar em sua origem. A criança desenvolve o sentimento de apego ao primeiro objeto que é inserido na boca, sendo estimado por ser o substituto do mamilo. Essa assimilação ocorre por volta do terceiro e quarto mês de vida. A manutenção da sucção, após a fase reflexa, pode ser decorrente de problemas psicológicos, ambientais (ciúmes, necessidade de atenção) e, até mesmo, 
distúrbio alimentar (GISFREDE; ROSA, 2016). Dessa forma, o hábito de sucção da chupeta pode trazer consequências emocionais para criança, causando dependência do objeto, o que acaba dificultando a sua remoção:

[...] comecei pedindo na escolinha para as professoras, não deem durante o dia [...] ela chorava e não queria mais ir para a escola (P7).

\begin{abstract}
Ah foi difícil, foi complicado, nos primeiros dias eu tive que me fazer de surda, matar no peito, porque ela estava em abstinência mesmo. É um vício que ela tinha, ela era super dependente. [...] fingi que não estava escutando e ela passou dois, três dias assim de mau humor com a cara fechada, com cara de choro [...]. Eu tinha aquela ideia de que ah o bico a hora que eu quiser eu tiro só que [...] dependia do bico até para dormir de noite e aí foi muito mais difícil. Aí que eu vi que a coisa era séria, não recomendo para ninguém, não recomendo mesmo (P5).
\end{abstract}

De acordo com o depoimento de P5, após a remoção da chupeta a criança demonstrou sofrimento frente à ausência da mesma, caracterizando um dos efeitos decorrentes do vício do objeto. Também, é possível observar o esforço do familiar para superar a utilização do recurso disposto como coadjuvante para os cuidados com a criança, além do cuidado para tomar as atitudes adequadas frente a essa situação.

O período em que o hábito de sucção não nutritiva é instaurado deve ser levado em consideração, uma vez que presente nas primeiras semanas de vida do bebê pode ocasionar problemas relacionados à amamentação. O período e a forma de aleitamento do bebê também parecem estar relacionados a utilização dos hábitos não-nutritivos, uma vez que crianças que recebem o aleitamento materno (sucção do peito) tem menor chance de desenvolverem hábitos bucais deletérios (GISFREDE; ROSA, 2016).

[...] ela chegava sempre com aquele bico na boca e não tirava para nada. Quando ela parou de chupar bico, na primeira semana, as professoras já comentaram [...] abriu a boca, falou, começou a falar, conversa, conversa [...]. A personalidade dela mudou por causa do bico (P5).

Esse depoimento reflete a alteração do comportamento da criança relacionado ao uso da chupeta, emergindo a fuga da interação social através do objeto, podendo estar relacionado à insegurança ou medo, após a criança vivenciar esse processo social de forma compulsória pela remoção do artefato, sugere-se a aquisição de segurança e confiança através da melhora nos relacionamentos. Destaca-se a mudança de personalidade notada pelos familiares (COLETTI; BARTHOLOMEU, 1998). Crianças ansiosas, estressadas ou tensas têm maior probabilidade de ter hábitos deletérios do que as que são consideradas calmas (MARCHESAN; GOMES; ZORZI 1996).

[...] com a função de vocês terem ido na escola ele até botou o biquinho na árvore, mas daí em seguida ele ficou doente e claro quando fica doente a primeira coisa que eles querem é o bico [...]. Ele ficou doente aí acabou que, 
ele pegou o bico por isso, mas ele estava indo no embalo ali dos colegas, ele estava gostando da ideia (P3).

[...] eu tinha tirado, vamos supor, bastante o bico dele, só pegava mesmo na hora de dormir no último sono ele pegava. Só com a função da vinda da irmã aí ele me pediu a função do bico (P8).

P3 apresenta em seu relato o fato de ceder ao desejo da criança pela chupeta por causa da doença instalada, como uma justificativa para a reintrodução do hábito. Por outro lado, com base no depoimento de P8, percebe-se que a criança voltou a usar a chupeta, devido a chegada de um novo membro na família, essa situação alude a insegurança da mesma frente ao desconhecido e a perda de atenção. Ressalta-se que a instalação do hábito de sucção não nutritiva pode ocorrer em consequência do nascimento de um irmão (JORGE et al., 2000). Ainda, estudo destaca que os primogênitos usaram menos chupeta se comparadas às crianças que possuíam irmãos (ALIBONI; ALFIE; PASTRANA, 2002).

Outro ponto observado nas falas dos participantes, diz respeito à influência dos pares na adoção de determinadas condutas pelas crianças:

[...] ele começou a pedir novamente o bico, porque os colegas acho que voltaram com o bibi que eles chamam, e aí ele começou a querer pedir o bico... (P4).

Essa fala revela que a continuidade do hábito pode ser influenciada pelo ambiente em que a criança se encontra a maior parte do tempo, no caso a escola, sendo o hábito atribuído aos costumes e a cultura dessa população, e a reprodução por parte da criança inserida nesse meio social (LARSSON, 1985). Diante do exposto, fica claro que a permanência do hábito não se relaciona com a complementação da sucção, aludindo falta de informação por parte dos familiares que não incentivam a descontinuação do hábito.

A seguir, no depoimento de $\mathrm{P} 4$, percebe-se que o hábito de sucção não-nutritiva é usado como forma do familiar proteger a criança e recompensar situações e mudanças emocionais, assim como minimizar possíveis sentimentos como ansiedade ou culpa frente à determinada situação. Essas ações, muitas vezes, podem ser reflexo da inabilidade da criança em agir frente a situações de estresse, em que a mesma apresenta ansiedade, levando, na maioria dos casos, a um comportamento infantil de regressão (FREUD, 1973). Ademais, os hábitos classificados como compulsivos, os quais são incorporados à personalidade da criança, são considerados por ela refúgio ao sentir-se ameaçada (FINN, 1982).

[...] tem dias que ele está muito carente. Hoje mesmo, por eu ter explicado que ele iria vir aqui, eu estou com o bico na bolsa (P4). 
É esperado que a sucção não-nutritiva seja abandonada pela criança em média aos três anos de idade, pois é quando inicia seu desenvolvimento psicológico e ela tende a interromper hábitos relacionados à fase oral (FREUD, 1973; TOMASI; VICTORA; OLINTO, 1994). Para Moyers (1991) é considerado normal a duração do hábito de sucção não-nutritiva até os três anos de idade, contudo, a frequente utilização da chupeta em crianças brasileiras estende-se além dos quatro anos. Isso é demonstrado em uma pesquisa que indicou que $37,8 \%$ e $38,9 \%$ das crianças com 4 e 5 anos, respectivamente, ainda possuíam o hábito de sucção não nutritiva (SANTOS et al., 2009).

A persistência do hábito de sucção da chupeta pode acarretar prejuízos à oclusão e alterações orofaciais que comprometem o crescimento harmônico da face (MOYERS, 1991; SANTOS et al., 2009). Nesse contexto, observou-se em uma pesquisa que avaliou como os hábitos deletérios afetam a oclusão, que a prevalência de má oclusão foi 5,46 vezes maior em crianças que utilizavam chupeta comparadas às que não a utilizavam (TOMITA; BIJELLA; FRANCO 2000). Ainda, crianças que possuem o hábito de sucção não nutritiva apresentam quatro vezes mais chance de ter mordida cruzada posterior e 14 vezes mais chance de desenvolver a mordida aberta anterior (SERRA-NEGRA; PORDEUS; ROCHA JUNIOR, 1997). Frisa-se que a perpetuação do hábito de sucção de chupeta além de causar deformidades dentárias impede que a língua exerça uma posição adequada prejudicando a correta deglutição e dificultando o desenvolvimento da linguagem da criança a nível articulatório e linguístico (CANONGIA; COHEN; RÉGNIER, 1990).

Os participantes relataram em seus depoimentos perceberem os prejuízos causados pela sucção da chupeta:

\section{[...] ela parou de chupar bico começou a falar, conversa, conversa, desenvolver a arcada dela, já estava ficando bem para frente, já melhorou, notei, bah (P5). \\ [...] já está prejudicando os dentes dele. A pediatra me disse que o céu da boca dele já está se fechando, aí disse que tinha que largar o bico o quanto antes (P6).}

Nessas falas, fica claro que o hábito de sucção não-nutritiva estava causando alterações nos tecidos dentários e esquelético das crianças, isso é determinado pelo tempo de realização do hábito de sucção da chupeta, sua frequência e a duração dessa pressão inadequada (MOYERS, 1991). Além disso, ressalta-se que após a remoção do hábito ocorre a autocorreção da má oclusão, considerada fisiológica, que pode ocorrer até dois a três anos de idade, dependendo do padrão dento-facial da criança, da capacidade da sua musculatura peribucal, da severidade da má oclusão e de outros hábitos (MOYERS, 1991; 
TOMITA; BIJELLA; FRANCO, 2000; DUQUE; ZUANON, 2006). É interessante destacar que, com o abandono do hábito de sucção de chupeta/mamadeira, crianças de quatro a seis anos de idade tiveram a diminuição e o fechamento da mordida aberta anterior (BONI; VEIGA; ALMEIDA 1997).

A seguir, nos depoimentos de P9 e P7, percebe-se o sentimento de impotência, dúvida e dificuldade dos pais frente ao desafio da remoção do hábito de sucção de chupeta e da adoção da abordagem adequada a ser usada com seus filhos a fim de não causar danos psicoemocionais:

[...] porque nós pais, a gente quer tirar, mas não consegue [...] Não sabe qual atitude tomar, drasticamente não dava para tirar [...] Nós já tínhamos tentado com menos idade [...] ela entregou para o Papai Noel e não manteve. Aí chorou e colocava tudo na boca [...] não conseguia dormir (P9).

[...] já estávamos incentivando em casa né, mas estava difícil. Só nós os dois batalhando a gente tirava e ele pedia (P7).

É evidente a dificuldade dos pais em manter uma postura incisiva frente à remoção do hábito de sucção da chupeta, isso ocorre, muitas vezes, por não saberem qual método utilizar e se o que eles utilizaram não acarretará consequências ao filho pela retirada do objeto estimado. É interessante observar, em um estudo realizado com os pais de crianças que possuíam o hábito de sucção da chupeta, que dentre os métodos de remoção do hábito os mais utilizados foram a interrupção abrupta, negando a chupeta para a criança; o uso de explicações por parte dos pais e de profissionais; o uso de substâncias na chupeta; o aconselhamento e sensibilização das crianças. O mais usado foi a interrupção abrupta, contudo, o mais eficiente foi as explicações dos profissionais (DEGAN; PUPPINRONTANI, 2004). Tartaglia et al., (2001) relataram que além da conscientização sobre os efeitos, método mais utilizado, os pais usaram de repreensões ou brigas para remover o hábito, além da troca por presentes.

Ele vai trocar por um brinquedo no final do ano (P4).

Nesse caso, a troca do bico por um presente é usada como recompensa e transferência do prazer que a criança sentia por meio da chupeta, para outro objeto. Vale salientar ainda, que o sucesso do tratamento depende essencialmente da aceitação da criança, prevenindo quaisquer consequências (COLETTI; BARTHOLOMEU, 1998). Nessa perspectiva, observa-se no depoimento de P7, que ao relatar sua experiência de remoção da chupeta, o familiar demonstra a dificuldade sentida quanto ao abandono do hábito deletério, por meio de um método abrupto. Assim, a falta de explicações acerca do motivo da entregado objeto estimado para um personagem, pode acarretar em um trauma. 
Chupei até lá uns sete anos eu acho, foi uma dificuldade assim né. Era para dar para o coelhinho, era para dar para o Papai Noel [...] para mim foi doloroso me lembro até hoje assim (P7).

A estratégia motivacional para a remoção do hábito de sucção da chupeta (PEREIRA; SCHARDOSIM; COSTA, 2009) usa uma abordagem de conscientização das crianças para o abandono do hábito deletério, sobre as sequelas que a chupeta acarreta, por meio do desenvolvimento de atividades lúdicas e que acontece de forma gradual:

[...] ela nunca mais chupou, nunca, nunca mais (P10).

[...] e ela chupa só quando ela está com sono mesmo, mas quando ela dorme, ela larga o bico e não pega mais (P1).

Não, não depois do projeto de vocês (P7).

Nos depoimentos, a seguir, nota-se a diminuição da frequência do hábito em crianças que não o abandonaram completamente:

[...] tem dias que ele dorme sem e tem dias que ele implora e chora até a gente ceder [...], mas não usa mais o dia inteiro, e é só eventualmente à noite que ele pede (P4).

[...] já foi um grande avanço tirar do dia, pelo jeito que ele falava de bico na boca, direto $[. .$.$] diminuiu bastante (P6).$

Não, antes ela chupava mais, ela chupava mais o bico (P1).

Essas situações são positivas, uma vez que estão diretamente relacionadas com a Tríade de Graber, na qual as alterações bucais e esqueléticas dependem da intensidade, frequência e duração do hábito deletério, com efeito, ao ser diminuída a frequência do hábito, suas consequências serão menores (GRABER, 1958). Além disso, a diminuição do hábito faz com que ele possa ser removido por completo mais facilmente, porque vai diminuindo a importância e dependência ao objeto.

É pequeno o percentual de crianças que substitui o hábito de sucção da chupeta, após sua remoção, por outro hábito (COLETTI; BARTHOLOMEU, 1998). Isso pode ser observado em estudo que demonstra que $81,5 \%$ das crianças não adquiriram novos hábitos, em contrapartida, 18,5\% substituíram o mesmo por hábitos como cheirar fralda, mastigar a camisa, roer unhas, entre outros (MARTINS et al., 2010). Das crianças participantes da estratégia motivacional apenas uma substituiu o hábito de sucção da chupeta por outros:

[...] ela entregou, sabe. Foi bem corajosa só que ela ainda está com aqueles hábitos de pôr a mão na boca, a unha, tem o moletom que tem que cuidar. Aí agora o controle, senão ela briga, porque já deixou faz um tempãoe então, está adquirindo outros hábitos, não tem porque né e a afilhada do meu marido tem 16 anos e chupa o dedo, aí nós temos uma baita preocupação[...]. Aí todo dia nós estamos falando, falando, falando, fazendo tirar (P9). 
Na fala de P9 fica clara a aquisição de novos hábitos por parte da criança, isso pode ocorrer como forma de compensar o prazer e a segurança que ela tinha com a chupeta através de outros objetos. Apesar de ser mínima a quantidade de crianças que fazem essa substituição, é evidente a preocupação dos familiares, especialmente em relação ao hábito de sucção do dedo. Esse realiza maior pressão se comparado com a chupeta e está sempre disponível dificultando a desinstalação do hábito (CAMARGO; MODESTO; COSER, 1998). Logo, nesses casos o uso da chupeta é considerado menos nocivo e indicado com disciplina a fim de evitar danos, sendo restrito à hora de dormir (PLANAS; SIMÕES, 1988; MASCARENHAS, 1999).

\subsection{Reprodução cultural do uso da chupeta}

A necessidade de adquirir a chupeta como item do enxoval do bebê, funciona como uma das ações de preparação para a chegada da criança, tendo significado especialmente para a mãe que possui, muitas vezes, a necessidade de se sentir preparada (SERTÓRIO; SILVA, 2005). Isso pode ser constatado nos depoimentos dos participantes desta pesquisa:

A avó materna, a minha mãe, ah tem que ter bico, nós já compramos a chupeta. Aí, já tinha comprado, já estava lá esperando, só que foi minha mãe, ah tem que dá o bico que o bico acalma, que o bico é bom que o bico é bom, e eu era marinheira de primeira viagem, não sabia o que fazere então, dá o bico (P9).

[...] já levei para o hospital, sei que é errado, a gente sabe né (P7).

Segundo o discurso dos participantes, percebe-se que os familiares já haviam adquirido a chupeta antes mesmo do nascimento do bebê, levando-a para a maternidade. Observa-se que sua utilização é frequente pelas crianças na maternidade, apesar das iniciativas governamentais desestimularem ou até mesmo impedirem a propaganda e o uso do objeto nos referidos locais (SERTÓRIO; SILVA, 2005). Destaca-se a iniciativa dos Hospitais Amigos da Criança que apoiam, protegem e promovem o aleitamento materno através dos "Dez passos para o sucesso do aleitamento materno" preconizado pela OMS/Unicef, que inclui não dar bicos artificiais ou chupetas a crianças amamentadas no peito, representando uma experiência de sucesso para o aumento das taxas de amamentação (WORLD HEALTH ORGANIZATION; UNICEF, 1989; LAMOUNIER et al., 2008). No entanto, no ano de 2019 houve uma atualização destes critérios em que 
as mães devem ser orientadas sobre o risco da chupeta, ao invés de simplesmente proibir o seu uso nas maternidades (WORLD HEALTH ORGANIZATION; UNICEF, 2019).

Estudo aponta que antes mesmo de irem para o hospital metade das mulheres já possuíam a chupeta (VICTORA et al., 1997). Isso mostra a expectativa dos pais com relação à chegada de seus filhos, a qual é extravasada por meio dos preparativos que incluem a obtenção do objeto, antecipando a possibilidade da criança necessitá-lo (SERTÓRIO; SILVA, 2005). Além disso, é enraizado na sociedade o costume da inclusão da chupeta como item importante junto aos outros objetos considerados ao enxoval do bebê, sendo incorporada em seu vestuário (FÓFANO et al., 2009; SOARES et al., 2003; SERTÓRIO; SILVA, 2005; TOMASI; VICTORA; OLINTO, 1994).

[...] levaram lá para maternidade [...] já tentaram dar para ela [...] ela já aceitou, ela gostava [...]. Com certeza ele foi dentro da bolsa (P10).

[...] porque a gente ganha, as pessoas adoram dar bico né [...]e então, tipo, as pessoas acabam que dão o bico né e aí claro, ele vai ganhando e ele tem um monte de bico. Aí levei para o hospital e acabou que eu dei o bico e ele pegou (P3).

No depoimento de P3, percebe-se que a chupeta é utilizada como forma de presentear os familiares pela vinda do bebê, sendo considerado um objeto querido e necessário para os pais com a chegada de seus filhos. Sob essa ótica, a diversidade de cores, formas, marcas, desenhos, seu fácil acesso e baixo custo despertam irresistível atração para o consumo deste artefato (MODESTO; CAMARGO, 1998; CAMARGO; MODESTO; COSER, 1998). Nota-se ainda no depoimento de P10, a relação da chupeta com o zelo às crianças, sendo o oferecimento do objeto considerado algo bom e agradável para elas, especialmente quando a criança aceita, o que identifica o gosto pelo objeto, na percepção dos familiares.

É preciso ressaltar que a chupeta terá um papel importante para crianças que necessitem da complementação de sucção, principalmente para aquelas em que a amamentação através do seio materno não for possível. O que é questionável é a oferta do objeto em livre demanda para todas as crianças, independente de ter ou não a necessidade de uso, simplesmente por fazer parte do universo infantil e por ser um costume transmitido através de gerações.

De acordo com Sertório e Silva (2005) a chupeta apresenta uma face figurativa e uma simbólica, sendo a primeira considerada a percepção de sua utilidade pela mãe, e na face simbólica a chupeta significa um objeto representativo do bebê e complementar de 
sua figura. Essa situação pode ser observada no depoimento de P5, na percepção do participante a chupeta é simbolicamente considerada como um elemento da criança:

[...] faz parte da criança, desde que nasceu (P5).

Os depoimentos a seguir refletem o valor da chupeta para os familiares, o que faz com que eles se empenhem e até insistam em sua introdução precoce. Sua utilização é atribuída pela maioria das mães por ser a maneira mais fácil de acalmar a inquietação natural dos recém-nascidos, solucionar as manhas infantis, manter os bebês sossegados e satisfazê-los entre os intervalos de amamentação (TOMASI; VICTORA; OLINTO, 1994). Entretanto, quando a chupeta é usada em qualquer incômodo ou desconforto, leva a criança a procurar prazer de forma simples e fácil, porém vazia, uma vez que perde o estímulo para as descobertas necessárias ao seu desenvolvimento (KLATCHOIAN, 2002). Segundo Moscovici (1978) as crenças da sociedade podem ser utilizadas como explicação para seus comportamentos, estes estão logicamente ligados às crenças representacionais, contudo as consequências não estão.

$\mathrm{Na}$ verdade foi com três meses que eu consegui fazer com que ela pegasse o bico. Eu já estava assim desistindo, aí ela pegou o bico (P8).

[...] a parte do estímulo foi minha, desde o primeiro momento, foi porque aquela coisa que a gente tem de cultura $(\mathrm{P} 4)$.

Ela começou assim com uns três, quatro meses.Na verdade, eu tentava e ela, bebê recém-nascido não gosta de bico né, eles ficam cuspindo, e eu fui insistindo, insistindo, até que ela pegou o bico (P5).

As falas dos depoentes refletem a importância do uso da chupeta para os pais significando a representação do cuidado, proteção e carinho que as mães têm ao oferecer a chupeta para seus filhos, o que estimula sua utilização. (SIMIONI; COMIOTTO; RÊGO, 2005) observaram em seu estudo que na visita domiciliar mais da metade das crianças participantes utilizavam a chupeta e que muitas crianças inicialmente a rejeitaram, contudo, habituaram-se pela persistência da mãe. Ainda, um trabalho que analisou os discursos das mães estudadas, notou a presença de representações sociais no que diz respeito à chupeta, identificando que a mesma é um auxílio para a mãe, ademais, ressalvou a decepção das mães quando a criança não aceitou o objeto, achando que perderam um ajudante no cuidado de seu filho (MARQUES et al., 2009). Desse modo, sua utilização vai além da relação com a função de sucção não-nutritiva, estando relacionado com a reprodução do seu uso (SOARES et al., 2003; SERTÓRIO; SILVA, 2005; FÓFANO et al., 2009). 
O uso da chupeta é influenciado por determinantes ambientais, socioeconômicos e culturais (SOARES et al., 2003; SERTÓRIO; SILVA, 2005). Instituiu-se uma relação simbólica entre a antecipação da calma e do conforto e a chupeta, atribuindo a ela um caráter protetor da criança (SERTÓRIO; SILVA, 2005; FÓFANO et al., 2009).

[...] ele nasceu e chorava incessantemente [...] o bico era um calmante, porque a gente botava aquela funchicorea, a gente botava mel e aquilo para nós era uma tentativa de ajudar ele a parar de chorar. Então assim, eu mesmo estimulei muito o uso do bico sem saber, porque para mim era um conforto para ele botar funchicorea ou mel para chupar (P4).

O uso de mel, artefatos açucarados e da funchicorea (pó fitoterápico para o tratamento de dispepsias intestinais como cólica e prisão de ventre) têm o intuito de acalmar os bebês e é descrito a milhares de anos por Sorano no século II e Oribasius no século IV, sendo reproduzido até os dias atuais. Isso pode ser observado em estudo, que ao avaliar a influência do ambiente socioeconômico no hábito de sucção da chupeta, 38,6\% dos pais mencionaram que utilizaram mel, açúcar ou algum doce na mesma, sendo esse um costume muito comum na população (ALIBONI et al., 2002). A constatação empírica desses meios fundamentada em experiências antecedentes fortalece $\mathrm{o}$ conhecimento de senso comum gerando satisfação dos usuários e colaborando para seu consentimento e utilidade, estimulando, assim, sua reprodução cultural (SERTÓRIO; SILVA, 2005). Ainda, foi observada a utilização de mel e açúcar pelos pais para a facilitação da introdução da chupeta em seus filhos (TOMASI; VICTORA; OLINTO, 1994). Nessa perspectiva, os profissionais da saúde necessitam sempre que possível orientar os familiares no sentido de evitar o mel, açúcar e produtos açucarados, reforçando com as mães os cuidados com a higiene oral (SIMIONI; COMIOTTO; RÊGO, 2005).

[...]ela se acalmava e aí depois com o passar do tempo acabou que ela acalmava para dormir de noite, sabia que ia ganhar o bico para dormir [...] mas basicamente foi para criança parar de chorar (P10).

[...] bico acalma né, para gente é bem melhor [...] está chorando dá o bico a criança se acalma né. Então, foi só por isso mesmo (P1).

[...] ele deu uma choradinha, diziam que o bico acalmava e eu disse está, vai acalmar, então dei o bico (P6).

Nota-se nas falas dos participantes que a chupeta é usada pelos responsáveis para adequar as ações do bebê em seu benefício, especialmente no que diz respeito a cessar o choro, na expectativa de que o comportamento das crianças seja o idealizado pelos pais (SILVA, 1996). Também, percebe-se fortemente a justificativa dos familiares a respeito da utilização da chupeta pelas crianças, de que a mesma as acalmam nos momentos de choro. Quando a criança chora, forma de comunicação com o meio, gera o sentimento de 
irritabilidade e ansiedade nos pais quando é constante e frequente. Isso traz insegurança aos familiares, provocando na mãe dúvidas acerca da sua competência de cuidar seu filho (LEBOVICI, 1987). No momento do choro há uma mudança na resposta fisiológica da estimulação diencefálica causada pelo mamilo ou chupeta, fazendo com que a criança cesse o choro (DOUGLAS, 1994). Dessa forma, nessas horas há uma cumplicidade entre a chupeta e a mãe, a fim de acalmar a criança, proporcionando à mãe segurança em relação aos cuidados com seu filho (SERTÓRIO; SILVA, 2005). Destaca-se que o uso da chupeta deve se restringir somente para a prática dos exercícios de sucção, não sendo usada como objetivo de cessar o choro da criança, decorrente de motivos tais como cólicas, consolo, desconforto ou solidão (CAMARGO; MODESTO; COSER, 1998).

Colettie e Bartholomeu (1998) ressaltaram que o hábito de sucção de chupeta inicia-se frequentemente logo ao nascimento do bebê com a finalidade de acalmá-lo. Ainda, verificaram que mais da metade das mães deu a chupeta aos seus filhos, e dessas $83,7 \%$ acreditavam que o intuito do seu uso era acalmar a criança (CAMARGO; MODESTO; COSER 1998). A chupeta representa um auxílio para a mãe e um calmante para o bebê, e ainda é uma alternativa de conforto quando a criança se encontra agitada (SERTÓRIO; SILVA, 2005). Essa situação é citada pelos depoentes, pois para os pais o uso da chupeta ocorre com o objetivo de acalmar a criança e solucionar seu problema de agitação (TOMASI; VICTORA; OLINTO, 1994):

[...] ela estava com sono, aí tu dá o bico ela acalmava, mas não que tenha me causado problema não ter o bico para fazer isso (P10).

Emerge na declaração de P10 que o familiar não apresentava dificuldade em acalmar a criança sem o bico, contudo usava o mesmo para exercer esse papel. A introdução da chupeta está relacionada, muitas vezes, mais à comodidade parental do que às necessidades extras de sucção propriamente dita da criança (PINTO et al., 2003). Ainda, o hábito pode ser estimulado com o intuito de liberar o familiar para executar suas tarefas e a chupeta passa a ser usada como um objeto de distração do bebê (SOARES et al., 2003; TOMASI; VICTORA; OLINTO, 1994). Com efeito, sua utilização é mais uma necessidade dos pais do que da própria criança (DEGAN; PUPPIN-RONTANI, 2004).

A criança possui a atividade reflexa de sucção, fundamental para sua nutrição e crescimento, garantindo uma rápida maturação neuromuscular das estruturas orais (DOUGLAS, 1994). A melhor forma de saciar sua necessidade de sucção é através do aleitamento materno, ao invés da mamadeira ou chupeta, sendo a amamentação a melhor forma de prevenção dos distúrbios oclusais. Quando a amamentação é possível de ser 
realizada, somente através do ato de mamar no seio materno, a chupeta não se faz necessária (MASCARENHAS, 1999). Praetzel et al., (2002) ao relacionar o tipo de aleitamento materno com a utilização da chupeta em crianças de 0 a 6 meses, evidenciou uma relação inversamente proporcional entre o uso da chupeta e o tempo de aleitamento no peito. Todavia, com o avanço industrial, tentam-se suprir as necessidades naturais por mantimentos processados, chupeta e mamadeiras, objetivando compensar a amamentação, assim a tendência é abdicar ou diminuir o seu tempo (MASCARENHAS, 1999).

O oferecimento da chupeta pelas mães para seus filhos pode ser realizado como forma de ocultar a insegurança e a ansiedade das mesmas com a amamentação. Isso necessita ser levado em consideração no momento da abordagem dos pais para informálos a respeito das consequências do hábito de sucção da chupeta para as crianças, de modo que, nesses casos, deve ser feita a tentativa de solucionar os problemas da mãe ao invés de simplesmente remover a chupeta de seus filhos (LAMOUNIER, 2003). É de extrema importância que ações assistenciais padronizadas que compreendam as necessidades psicológicas das mães, tais como a segurança frente aos cuidados com seus filhos, possam ser desenvolvidas no sistema de saúde, destacando uma abordagem que compreenda o núcleo familiar (SERTÓRIO; SILVA, 2005). Nesse sentido, a utilização do objeto deve ser encarada como um alerta para os problemas relacionados à amamentação (LAMOUNIER, 2003).

[...] aí na hora que eu não conseguia amamentar, o bico eu acho que iria acalmar ele um pouco. Todo mundo diz que o bico ajuda a acalmar, né (P8).

Estudo discute que na Suécia atualmente as mães possuem as informações necessárias no que diz respeito à amamentação, entretanto o estilo de vida atual dificulta a criação de seus filhos tradicionalmente (tempo disponível para que os filhos mamem à vontade) (LINDSTEN; LARSSON, 2009). Isso pode ocorrer devido a longas jornadas de trabalho extradomiciliar e tarefas diárias da mãe, as quais diminuem o tempo de convívio com seus filhos e em inúmeras vezes não apresentam condições de amamentá-los (VELLINI, 2002). Essa indisponibilidade de tempo gera preocupação nos pais, entretanto as leis de proteção à infância lutam para superar essa dificuldade (MASCARENHAS, 1999). Nessa perspectiva, muitas mães dão a chupeta aos seus filhos com o intuito de exercer um controle no comportamento da amamentação, organizando os horários da mesma, de acordo com sua disponibilidade (LAMOUNIER, 2003; SERTÓRIO; SILVA, 2005). O uso racional da chupeta pode ser observado quando ela for utilizada após a 
amamentação, se o bebê ainda apresentar a necessidade de sucção (CORRÊA, 2010). Referências direcionadas a essa prática são citadas, a seguir, pelos familiares representando uma vantagem para a utilização da chupeta, a fim de complementar a sucção da criança quando a mãe apresenta indisponibilidade ou empecilho à prática da amamentação no tempo necessário.

[...] minha preocupação é depois com o trabalho [...] ela queria fazer meu seio de bico né. Aí então vamos botar o bico nela, depois também eu tinha que voltar ao serviço (P8).

Pinto et al., (2003) observou que a iniciação do uso da chupeta nos bebês é gerida por uma série de fatores econômicos, sociais e culturais. Sua prevalência se altera nos continentes devido ao ambiente e às culturas diferenciadas, sendo maior em países industrializados, revelando a magnitude na sociedade menos favorecida economicamente (TOMASI; VICTORA; OLINTO, 1994). Em uma pesquisa realizada nos Emirados Árabes, notam-se hábitos culturais diferentes das mães ao acalmar seus bebês, os quais compreendem segurar e carregar a criança, amamentá-la no seio, permitir a sucção do dedo, usar chás, banhos e massagens. Dessa forma, 92\% das mães optaram por não dar a chupeta aos seus filhos com o intuito de proporcionar um bom desenvolvimento dos dentes, contudo, outros hábitos culturais foram empregados (ABDULRAZZAQ; AL KENDI; NAGELKERKE, 2009). Já na cultura brasileira o uso da chupeta é fortemente arraigado, até mesmo pela população com maior acesso à informação (SOARES et al., 2003).

Ah quem deu foi eu né, instinto de mãe né. Eu dei quando nasceu, normal, é normal... (P2).

Destaca-se no relato de P2 que a chupeta é tratada com normalidade sendo um hábito cultural da sociedade. Estudos demonstram que a utilização da chupeta é um comportamento normal, desejável e positivo, sendo oferecido insistentemente pelas mães para que as crianças a aceitem (LAMOUNIER, 2003; VICTORA et al., 1997; ZUANON et al., 2000). Percebe-se também nos depoimentos que foi a mãe que ofereceu a chupeta ao seu filho. Soares et al., (2003) constataram que durante o primeiro mês de nascimento do bebê a chupeta foi oferecida na maioria das vezes pela mãe, correspondendo a $72,2 \%$. Estudos mostraram que mães que oferecem a chupeta aos seus filhos apresentam grande expectativa sobre seu desenvolvimento e crescimento, ansiedade frente ao choro da criança, preocupação com seu meio social, sendo mais sensíveis à crítica e se comparam à outras mães, demonstrando falta de autoconfiança. Por outro lado, mães confiantes em 
relação à amamentação, relatam que a criança seja menos afetada pela utilização da chupeta (LAMOUNIER, 2003; VICTORA et al., 1997).

[...] ela não pegava bico de jeito nenhum e o único bico que eu consegui fazer ela pegar foi aquele de borracha, os de silicone ela não pegava, e a minha vizinha deu um bico de borracha e ela pegou (P1).

Ofereci o bico desde o segundo dia, porque eu fiz cesárea, o leite não descia, todas as pessoas que entravam no quarto diziam:- ah tem que dar chupeta, ah tem que dar chupeta [...]acalmava foi uma coisa boa muito boa (P9).

[...] minha madrinha [...] sempre comprava um bico e todo mundo dizia agora que tu deu tem que deixar, e dizia não, mas ela já está grande [...]. Eu ia lá na casa do dindo e eles sempre compravam, ah, vamos lá que eu vou comprar um bico (P9).

Percebe-se nos depoimentos a insistência dos indivíduos ao oferecer o bico para as crianças, mostrando um compromisso que vai além do núcleo familiar, envolvendo também o meio social em que estão inseridas, o que pode ser explicado pelos costumes relacionados ao uso da chupeta e a reprodução dessa cultura na sociedade, que ocorre muitas vezes de maneira irracional. Vilfredo Pareto formulou uma teoria a fim de explicar aspectos não-lógicos da vida social (JOHNSON, 1997). A maioria dos comportamentos humanos são conduzidos por uma quantidade fixa de motivações psicológicas universais, as quais ele designou de resíduos. Além disso, a vida social compreende as derivações que são os esclarecimentos que as pessoas dão sobre seu comportamento e dos sistemas sociais em que ocorrem. Elas são de extrema importância porque atuam como justificativa ideológica, servindo como base das ações sociais (JOHNSON, 1997). Nesse sentido, derivações tais como crenças e os intuitos dos sujeitos sociais podem justificar e explicar a origem de seus atos.

Identifica-se nos relatos dos participantes, a reprodução cultural através das gerações:

[...] algum familiar, minha mãe talvez, meu marido [...]. Minha mãe também era daquelas de dar o bico (P10).

[...] acredito que sim, eu ganhei um bico da mãe (P3).

[...] eu chupei bico sim [...] A gente chorou uma noite pedindo o bico e depois nunca mais, então acho que não foi um sofrimento que nem eles sofrem né (P3).

[...] a minha irmã chupou, mas ela chupou até os treze. Naquela época o pai e a mãe não levavam no dentista não, tanto fazia. (P6).

Observa-se nos depoimentos a reprodução dos saberes de pais para filhos, sendo que a maioria dos pais que utilizaram a chupeta ganhou o objeto de suas mães, as quais também o deram aos seus netos. Filhos de mães que usaram a chupeta em sua infância 
têm mais risco de possuírem esse hábito quando comparados aos filhos de mães que não o tinham (SERRA-NEGRA et al., 2006). Estudo ressalta que pais que utilizaram chupeta quando crianças tiveram uma chance 4,2 vezes maior de seu filho usá-la, já as mães tiveram 5,25 vezes mais risco de seus filhos a usarem (ALIBONI et al., 2002). Além disso, mães que apresentam os hábitos iguais ao de seus filhos possuem mais dificuldade para sua remoção, uma vez que elas podem ficar mais compreensivas com os mesmos (SERRA-NEGRA et al., 2006).

Apesar de existir a percepção da necessidade de mudança, o estabelecimento de novos modelos e procedimentos não é aceito imediatamente. A mudança é racional enquanto os comportamentos são baseados em crenças, valores e normas culturais que são irracionais ou limitadamente racionais. A partir de uma visão coerente pode-se conduzir uma tentativa de intervenção, confrontando-se muitas vezes com a cultura, sendo sua transição determinada por um longo processo. Contudo, a cultura é transformável, sendo a primeira fase a indução da mudança, a fim de gerar a tomada de consciência (GOMES, 1994).

A simples transmissão de informações como método educativo não consegue por si só modificar padrões de comportamento e hábitos que têm fundo cultural e já estão enraizados nos costumes da população. A atividade educativa deve partir da captação dos valores dos sujeitos e buscar, a partir daí, a adequação das ações, com o objetivo de motivar os indivíduos a agir, respeitando suas particularidades (DADALTO; ROSA, 2013). Nesse contexto, Tamietti et al., (1998) sugeriram que uma abordagem participativa construída, partindo das representações sociais, substitua as tradicionais técnicas para a educação em saúde, e que conteúdos em saúde, especialmente saúde bucal, façam parte dos currículos escolares. A articulação da saúde e da educação oportuniza ações integradas que instigam a crítica e a reflexão das pessoas, além de possibilitar a preparação e a atualização dos educadores a fim de prover discursos voltados à saúde (MACIEL et al., 2010). Dessa forma, o fomento a mudanças e a conscientização dos indivíduos podem iniciar desde cedo. Também, Soares et al., (2003) considera importante debater com os responsáveis e a sociedade a respeito das vantagens e desvantagens relacionadas a utilização da chupeta, a fim de que a população faça escolhas conscientes. 


\section{Considerações finais}

Constatou-se, com a análise das entrevistas que a prática da utilização da chupeta está fortemente relacionada à cultura, e que os pais percebem este como um hábito comum e presente na criação de seus filhos, transmitido entre as gerações e que ocorre muitas vezes de forma irracional. Alguns pais ainda percebem que o hábito prolongado poder ser prejudicial, mas que enfrentam dificuldades para a remoção do mesmo, por isso entendem que a utilização de estratégias motivacionais educativas realizada nas escolas pode auxiliar nessa etapa, que para os pais é muito desafiadora.

Uma quantidade expressiva de mães ganha ou compra a chupeta, antes do nascimento de seus filhos, para incluí-la no enxoval do bebê e a leva para a maternidade. Assim, a utilização da chupeta se inicia a partir do nascimento da criança, sendo-lhe oferecida logo no hospital. Seu uso ainda é muito frequente, estando relacionado aos costumes e as crenças da população, apesar de muitas mães terem consciência das consequências desse hábito deletério.

Após o nascimento da criança, evidenciou-se a insistência dos pais para a introdução da chupeta em seus filhos, revelando sua importância e seu valor para o núcleo familiar e para as pessoas envolvidas. Além disso, o objeto representa proteção e amor dos pais para com seu filho, possuindo um papel coadjuvante no seu cuidado. Os principais motivos para sua utilização citados pelas mães foram o de acalmar a criança, cessar seu choro, distraí-la ou por costume, uma vez que todo mundo usa, estando sua utilização relacionada, muitas vezes, à comodidade parental.

A estimulação motora oral pode ser realizada por meio da amamentação somente, quando essa é possível, não sendo necessário o uso da chupeta. Entretanto, o estudo aponta a preocupação das mães com a indisponibilidade de tempo para amamentar devido ao trabalho extradomiciliar, oferecendo assim a chupeta para seus filhos como complementação da necessidade se sucção, o que com a frequência de sua utilização se torna um hábito. Quanto à origem do hábito de sucção, observou-se que pode ser de ordem fisiológica, problemas relacionados à amamentação, aprendizado e emocional, além se estar ligado a problemas comportamentais, desordens ambientais e psicológicas. Também, o objeto transmite segurança à criança que o assimila com a mãe, podendo trazer consequências emocionais como a dependência, dificultando sua remoção.

Espera-se que o hábito de sucção de chupeta seja interrompido até os três anos de idade, no entanto, notou-se que o mesmo se estende além dessa idade, acarretando 
prejuízos à oclusão e alterações orofaciais. Ainda, foi apontada a autocorreção da má oclusão após a remoção do hábito. A remoção do hábito de sucção de chupeta causa dúvidas nos pais relacionadas à sua abordagem e possíveis consequências psicoemocionais para a criança, além do empenho realizado pelos familiares para superar sua vinculação com o objeto como apoio para os cuidados com seus filhos. Há casos em que o abandono da chupeta causa ansiedade e irritação à criança, fato confirmado também neste estudo.

Ficou evidente que a prática da utilização da chupeta está fortemente relacionada à cultura, sendo tratada com normalidade e considerada desejável e positiva. Além disso, a maioria das crianças recebe sua primeira chupeta das mães, essa reprodução cultural por meio das gerações ocorre muitas vezes de forma irracional, pela reprodução de saberes aprendidos e pela constatação empírica baseada em experiências anteriores. Enfatiza-se que a cultura é transformável, sendo necessária uma abordagem participativa construída a partir das representações sociais que substituam as técnicas tradicionais de educação em saúde.

Nessa perspectiva, o uso da estratégia motivacional apresentada é recomendado para que seja realizada além da remoção do hábito de sucção da chupeta em crianças, transmissão de conhecimentos e conscientização de crianças e adultos, para a racionalização de suas decisões quanto à utilização do objeto.

\section{Referências}

AGURTO, P. V. et al. Frecuencia de malos hábitos orales y su asociación con el desarrollo de anomalías dentomaxilares en niños de 3 a 6 años del área Oriente de Santiago. Revista chilena de pediatría, Santiago, v. 70, n. 6, p. 470-482, nov. 1999.

ABDULRAZZAQ, Y. M.; AL KENDI, A.; NAGELKERKE, N. Soothing methods used to calm a baby in an Arab country. Acta Paediatrica, Al Ain, United Arab Emirates. v. 98, n. 2, p. 392-396, jan. 2009.

ALIBONI, V. G.; ALFIE. J. D.; PASTRANA, S. C. Uso Del Chupete: Hallazgos Preliminares. Arch. argent. pediatr. Buenos Aires, v. 100, n. 2, p. 114-119, 2002.

AMERICAN ACADEMY OF PEDIATRICS. Breastfeeding and The Use Of Human Milk. Pediatrics, Itasca, vol. 129, n. 3, s.p. mar. 2012.

BEE, H. O ciclo vital. Porto Alegre: Artes Médicas, 1997. 
BONI, R. C.; VEIGA, M. C. F. A.; ALMEIDA, R. C. Comportamento da mordida aberta anterior, após a remoção do hábito de sucção. J. bras. ortodontia ortop. maxilar, v. 2, n. 12, p. 35-40, nov./dez. 1997.

BRASIL. Ministério da saúde. Pesquisa de prevalência do aleitamento materno nas capitais e no Distrito Federal. Brasília: Ministério da Saúde. 2001.

CAMARGO, M. C. F.; MODESTO, A.; COSER, R. M. Uso racional da chupeta. J. Bras. Odontopediatr. Odontol. Bebe, Curitiba, v. 1, n. 3, p. 43-7, 1998.

CANONGIA, M. B.; COHEN, F. F.; RÉGNIER, G. M. C. Prevenindo os Distúrbios Orofuncionais. Rio de Janeiro: Medi Livros, 1990.

COLETTI, J. M.; BARTHOLOMEU, J. A.L. Hábitos nocivos de sucção de dedo e/ou chupeta: etiologia e remoção do hábito.Bras. Odontopediatr. Odontol. Bebe, Curitiba, v.1, n.3, p. 57-63, jul./set. 1998.

CORRÊA, M. S. N. P. Hábitos bucais. In: CORRÊA, M. S. N. P. Odontopediatria na primeira infância. São Paulo: Liv. Santos, 2010. p. 561-567.

DADALTO, E.C.V., ROSA, E.M. Aspectos culturais para a oferta da chupeta às crianças. Journal of Human Growth and Development, São Paulo, v.23, n.2, p. 231237, 2013.

DE MATOS, G. C. et al. A prevalência de hábitos orais em pré-escolares. Distúrbios da Comunicação, São Paulo, v. 29, n. 1, p. 68-76, mar. 2017.

DEGAN, V. V.; PUPPIN-RONTANI, R. M. Prevalence Of Pacifier-Sucking Habits And Successful Methods To Eliminate Them-A Preliminary Study. J. Bras.

Odontopediatr. Odontol. Bebe, Curitiba, v. 71, n. 2, p. 148-151, 2004.

DOUGLAS, C. R. Tratado de fisiologia aplicada às ciências saúde. 1. ed. São Paulo: Robe, 1994.

DUARTE, N. Formação do indivíduo, consciência e alienação: o ser humano na psicologia de A. N. Leontiev. Cadernos Cedes, Campinas, v. 24, n. 62, p. 44-63, 2004.

DUQUE, C.; ZUANON, A. C. C. Sucção de chupeta: implicações clínicas e tratamento. Rev. Paul. Odontol., São Paulo, v. 28, n. 1, p. 21-23, 2006.

EMMERICH, A. et al. Relação entre hábitos bucais, alterações oronasofaringianas e mal-oclusões em pré-escolares de Vitória, Espírito Santo, Brasil. Cad Saúde Pública, Rio de Janeiro, v. 20, n. 3, p. 689-697, out. 2004.

FENANDES, M. Z.; LIMA, M.C.M.P. A visão dos pais e professores sobre a ocorrência de hábitos orais deletérios em um grupo de pré-escolares. Rev. CEFAC, São Paulo, v.21, n.3, p. e14418, 2019.

FINN, S. B. Odontologia pediátrica. 4. ed. Mexico: Interamericana, 1982. 
FÓFANO, C. D. S. et al. Conhecimentos, atitudes e práticas maternas em relação ao uso da chupeta. Pesq Bras Odontoped Clin Integr., João Pessoa, v. 9, n. 1, p. 119-123, jan./abr. 2009.

FREUD, S. Oral habits. In: FREUD, S. Obras completas. Madrid, España: ed Nueva, 1973. p. 3379-3423.

GRISFREDE, et al. Hábitos bucais deletérios e suas consequências em Odontopediatria. Rev. bras. odontol., Rio de Janeiro, v. 73, n. 2, p. 144-149, abr./jun. 2016.

GOMES, A. D. Mudanca Organizacional: Mudar a Cultura ou Mudar de Estrategia? Análise Psicológica, Lisboa, v. 1, s. n., p. 15-30, 1994.

GRABER, T. M.The Finger-Sucking and Associated Problems. J Dent Child, Chicago, v. 25, n. 2, p. 145-51, july. 1958.

HANSON, M. L.; BARRET, R. H. Fundamentos da miologia orofacial. Rio de Janeiro: Enelivros, 1995.

JOHNSON, A. G. Dicionário de sociologia. Rio de Janeiro: Jorge Zahar Editor, 1997.

JORGE, M. L. R.; REIS, M. C. S.; SERRA NEGRA, J. M. C. Como eliminar os hábitos de sucção não nutritiva? J. Bras. Odontopediatr. Odontol. Bebe, Curitiba, v. 3, n. 11, p. 49-54, 2000.

KLATCHOIAN, D. A. Psicologia Odontopediátrica. 2. ed. São Paulo: Sarvier, 2002.

LAMOUNIER, J. A. O Efeito de Bicos e Chupetas no Aleitamento Materno. J Pediatr, Rio de Janeiro, v. 79, n. 4, p. 284-286, 2003.

LAMOUNIER, J. A. et al. O. Iniciativa Hospital Amigo da Criança, mais de uma década no Brasil: repensando o futuro. Rev Paul Pediatr, São Paulo, v. 26, n. 2, p. 161169, 2008.

LARSSON, E. The prevalence and aetiology of prolonged dummy-andfinger-sucking habits. The European Journal of Orthodontics, Oxônia, v.7, n.3, p.172-176, aug. 1985.

LEBOVICI, S. O bebê, a mãe e o psicanalista. Artes Médicas, 1987.

LINDSTEN, R.; LARSSON, E. Pacifier-Sucking and Breast-Feeding: A Comparison Between the 1960s and the 1990s. J Dent Child, Chicago, v. 76, n. 3, p. 199-203, sept. 2009.

MACIEL, E. L.N. et al. Aprendendo Saúde na Escola: a experiência de repercussões positivas na qualidade de vida e determinantes da saúde de membros de uma comunidade escolar em Vitória, Espírito Santo. Revista Ciência \& Saúde Coletiva, Espírito Santo, v.15, n. 2, p.389-396, fev. 2010. 
MARCHESAN, I. Q.; GOMES, I. C. D.; ZORZI, J. L. Tópicos em Fonoaudiologia. São Paulo: Lovise, 1996.

MARQUES, E. S.; COTTA, R. M. M.; ARAÚJO, R. M. A. Representações sociais de mulheres que amamentam sobre a amamentação e o uso de chupeta. Rev. Bras.

Enferm, Brasília, v. 62, n. 4, p. 562-569, jul./ago. 2009.

MARTINS, B. S. et al. Métodos usados para remoção dos hábitos de sucção de dedo e/ou chupeta em crianças do município de Mutum-MG. Braz J Health Res, Curitiba, v. 12 , n. 4, p. 19-25, 2010 .

MASCARENHAS, C. F. Sucção De Chupeta: Qual A Razão da Utilização da Chupeta no Recém-Nascido. Fono Atual, São Paulo, v. 3, p. 25-28, 1999.

MINAYO, M. C. S. O Desafio do Conhecimento: Pesquisa Qualitativa em Saúde. 13. ed. São Paulo: Editora Hucitec. 2004.

MODESTO, A.; CAMARGO, M. C. F. Chupeta: bandida ou mocinha. J APCD, São Paulo, v. 32, s.n., p. 29, 1998.

MOSCOVICI, S. A representação social da psicanálise. Tradução de Álvaro Cabral. Rio de Janeiro: Zahar, 1978.

MOYERS, R. E. Etiologia da maloclusão. Ortodontia, São Paulo, v. 4, p. 157-159. 1991.

PEREIRA, V. P.; SCHARDOSIM, L. R.; COSTA, C. T. Remoção do Hábito de Sucção de Chupeta em Pré-escolares: apresentação e avaliação de uma estratégia motivacional. Rev. Fac. Odontol, Porto Alegre, v. 50, n. 3, p. 27-31, set./dez. 2009.

PINTO, M. C. G. L. et al. Fatores sócio-econômico-culturais relacionados ao uso da chupeta em crianças de zero a quatro anos da cidade do Recife-PE. Arq. Odontol., Belo Horizonte, v. 39, n. 4, p. 285-296, 2003.

PLANAS, P.; SIMÕES, W. A. Reabilitação neuro-oclusal. Rio de Janeiro: Medsi, 1988.

PRAETZEL, J. R. et al. Relação entre o tipo de aleitamento e o uso de chupeta, J. Bras. Odontopediatr. Odontol. Bebê, v. 5, n. 25, p. 235-240. 2002.

SANTOS, S. A. D. et al. Hábitos de sucção não nutritiva em crianças pré-escolares. Jornal de Pediatria, Porto Alegre, v. 85, n. 5, p. 408-414, 2009.

SERRA NEGRA, J. M. C.; PORDEUS, I. A.; ROCHA JUNIOR, J. F. Estudo da associação entre aleitamento, hábitos bucais e maloclusões. Rev. Odontol. Univ. São Paulo, São Paulo, v. 11, n. 2, p. 79-86, 1997.

SERRA-NEGRA, J. M. C. et al. Hábitos bucais deletérios: os filhos imitam as mães na adoção destes hábitos? Revista Odonto Ciência, Porto Alegre, v.21, n. 52, p.146-152, abr./jun. 2006. 
SERTÓRIO, S. C. M.; SILVA, I. A. As Faces Simbólica e Utilitária da Chupeta na Visão de Mães. Rev. Saúde Pública, São Paulo, v. 39, n. 2, p. 156-162, 2005.

SILVA, H. C.; AMMON, I. O. N.; SILVA, R. H. H. Avaliação do paciente sobre ensino de práticas preventivas em Odontologia. Odontol. Mod., Santa Catarina, v. 12, n. 5, p. 46-53, 1985.

SILVA, L. A. Amamentar: uma questão de assumir riscos ou garantir benefícios. Rev. Esc. Enf. USP, São Paulo, v.30, n. 1, p. 170-1711, abr. 1996.

SIMIONI, L. R. G.; COMIOTTO, M. S.; RÊGO, D. M. Percepções maternas sobre a saúde bucal de bebês: da informação à ação. RPG Rev. Pos-grad, São Paulo, v. 12, n. 2, p. 167-173, 2005.

SOARES, M. E. M. et al. Uso de chupeta e sua relação com o desmame precoce em população de crianças nascidas em Hospital Amigo da Criança. J Pediatr, Rio de Janeiro, v.79, n. 4, p. 309-316, jul./ago. 2003.

TAMIETTI, M. B.; CASTILHO, L. S.; PAIXÄO, H. H. Educação em saúde bucal para adolescentes: inadequação de uma metodologia tradicional. Arq. Odontol, Cidade da revista, v. 34, n. 1, p. 33-45, set. 1998.

TARTAGLIA, S. M. A. et al. Hábitos orais deletérios: avaliação do conhecimento e comportamento das crianças e suas famílias. J. Bras. Odontopediatr. Odontol. Bebe, Curitiba, v. 4, n. 19, p. 203-209, 2001.

TOMASI, E.; VICTORA, C. G.; OLINTO, M. T. A. Padrões e determinantes do uso de chupeta em crianças. J Pediatr, Rio de Janeiro, v. 7, n. 3, p. 167-73, 1994.

TOMITA, N. E.; BIJELLA, V. T.; FRANCO, L. J. Relação entre hábitos bucais e má oclusão em pré-escolares. Rev Saúde Pública, São Paulo, v. 34, n. 3, p. 299-303, fev. 2000.

VELLINI, F. F. Hábitos em ortodontia. In: VELLINI, F. F Ortodontia: planejamento e diagnóstico clínico. 3. ed. São Paulo: Artes Médicas, 2002. p. 253-281

VICTORA, C. G. et al. Pacifier use and short breastfeeding duration: cause, consequence, or coincidence? Pediatrics, Itasca, v. 99, n. 3, p. 445-453, 1997.

WALTER, L. R. F.; FERELLE, A.; ISSAO, M. Odontologia para o bebê. São Paulo: ArtesMédicas, 1996.

WORLD HEALTH ORGANIZATION; UNICEF. Protecting, promoting and supporting breast-feeding: the special role of maternity services. Genebra, Suíça: World Health Organization. 1989.

WORLD HEALTH ORGANIZATION; UNICEF. Pacifiers: Counseling instead of prohibiting. The new Baby-friendly Hospital Initiative. Genebra, Suíça: World Health Organization. 2019. 
ZUANON, A. C.C. et al. Relação entre hábito bucal e maloclusão na dentadura decídua. J. Bras. Odontopediatr. Odontol. Bebe, Curitiba, v. 3, n. 12, p. 104-108, 2000.

Recebido em: 03 de setembro de 2017.

Aceito em: 12 de abril de 2019. 